\title{
Etnobotani Tumbuhan Upacara Adat Etnis Ngadha di Kecamatan Jerebu'u Kabupaten Ngada, Provinsi Nusa Tenggara Timur
}

\author{
Mariana Sada ${ }^{\mathrm{a}}$, dan Jumari ${ }^{\mathrm{b}}$ \\ ${ }^{a}$ Fakultas Pendidikan MIPA, IKIP Muhammadivah, Maumere, Sikka - NTT, Indonesia, email: nuwamar990@gmail.com \\ ${ }^{b}$ Fakultas Matematika dan Sains, Universitas Diponegoro, Semarang - Jawa Tengah, Indonesia, email: jumariundip@ gmail.com
}

\section{Article Info}

\section{Article history:}

Received 25 November 2018

Received in revised form 17 Desember 2018

Accepted 20 Desember 2018

\section{DOI:}

https://doi.org/10.32938/slk.v1i2.503

\section{Keywords:}

Etnis Ngadha, Konservasi, Tumbuhan,

Upacara adat

\section{Abstrak}

Etnis Ngadha merupakan salah satu kelompok masyarakat tradisional terbesar di Kabupaten Ngada. Kehidupan masyarakat etnis ini masih tetap berpegang teguh pada adat-istiadat warisan leluhur. Ciri khas komunitasnya adalah upacara adat. Penelitian ini telah dilakukan pad bulan Februari - Mei 2016 di desa Tiwuriwu, Watumanu dan Dariwali Kecamatan Jerebu'u, Kabupaten Ngada. Penelitian ini bertujuan untuk menginventarisasi jenis-jenis tumbuhan dan makna tumbuhan dalam pelaksanaan upacara adat serta upaya pelestarian yang dilakukan oleh masyarakat. Metode pengumpulan data dilakukan secara eksploratif, observasi partisipatif dan wawancara. Berdasarkan hasil penelitian diperoleh 60 jenis tumbuhan yang tergolong dalam 26 famili yang digunakan dalam upacara adat. Famili yang paling banyak digunakan adalah Poaceae 15 jenis, Fabaceae 8 jenis, Arecaceae 6 jenis, Musaceae dan Solanaceae masing-masing 3 jenis, sedangkan famili lainnya antara 1 sampai dengan 2 jenis. Masing-masing jenis memiliki makna spesifik dalam setiap upacara adat sesuai dengan maksud dan tujuan upacara tersebut. Bentuk kegiatan konservasi yang dilakukan masyarakat adalah membudidayakan tumbuhan tersebut di sekitar pekarangan rumah, kebun atau ladang milik mereka.

\section{Pendahuluan}

Indonesia dikenal sebagai negara megabiodiversitas karena kekayaan sumber daya hayati. Indonesia juga memiliki beragam etnis kurang lebih mencapai 300 kelompok etnis yang tersebar dari Sabang sampai Merauke yang memiliki kehidupan sosial dan budaya masing-masing. Kombinasi kedua kekayaan ini memunculkan beragam pengetahuan tradisional terkait pemanfaatan dan pengelolaan tumbuhan untuk berbagai kebutuhan hidup seperti sandang, pangan, papan, kesehatan dan kepentingan budaya. Salah satu pemanfaatan tumbuhan untuk kepentingan budaya dalam kehidupan masyarakat tradisional di Indonesia yaitu sebagai bahan dan sarana kelengkapan dalam kegiatan upacara adat. Tiap kelompok etnis tersebut memiliki beraneka ragam upacara adat ataupun ritual-ritual baik itu secara keagamaan maupun kepercayaan leluhur yang dilaksanakan dan dilestarikan oleh masing-masing pendukung kebudayaannya (Rohmah $d k k ., 2014$ )

Seiring dengan meningkatnya arus globalisasi dan modernitas mengakibatkan sebagian besar pengetahuan tradisional mengalami kemerosotan bahkan punah. Hal ini dikarenakan sifat pengetahuan tradisional yang bersifat adaptif dan dinamis serta didukung dengan pola pewarisan yang pada umumnya dilakukan secara oral mengakibatkan kualitas dan kuantitasnya semakin berkurang. Oleh karena itu, melalui kajian etnobotani ditekankan bagaimana mengungkapkan keterkaitan antara budaya masyarakat dengan sumber daya tumbuhan di lingkungan khususnya dalam upacara adat. Hal ini bertujuan untuk memperkuat basis masyarakat dalam menjaga kebudayaan setiap etnis.

Etnis Ngadha merupakan salah satu kelompok etnis terbesar di Kabupaten Ngada yang masih berpegang teguh pada adat dan istiadat warisan leluhurnya. Etnis ini dikenal sebagai penganut budaya Reba atau Ngadhu-Bhagha. Etnis Ngadha selalu memperingati setiap peristiwa penting dalam kehidupan seperti kelahiran, pernikahan, kematian, kegiatan pertanian dan lainnya dengan upacara adat. Masyarakat meyakini bahwa upacara adat menjadi satu landasan karakteristik dalam menjalankan relasi antara manusia dengan manusia, manusia dengan lingkungannya, manusia dengan roh leluhur ataupun roh-roh lainnya serta manusia dengan sang Pencipta (Arndt, P., 2005; Arndt, P, 2007).

Kecamatan Jerebu'u merupakan salah satu daerah pusat penyebaran etnis Ngadha yang kaya akan berbagai peninggalan budaya dan tradisi yang masih sangat alami. Akan tetapi, informasi dan data mengenai potensi serta pemanfaatan sumber daya hayati di Kecamatan Jerebu'u khususnya dalam kegiatan upacara adat masih sangat minim. Oleh karena itu, perlu digali dan didokumentasikan agar pengetahuan ini tetap terjaga. Penelitian ini penting dalam menunjang upaya pelestarian sumber daya hayati.

\section{Metode}

Penelitian ini dilakukan di desa Tiwuriwu, Watumanu dan Dariwali Kecamatan Jerebu'u pada bulan Februari sampai Maret 2016. Pengumpulan data dilakukan dengan menggunakan metode survei eksploratif, observasi partisipatif dan wawancara. Survei eksploratif bertujuan untuk menginventarisasi jenis-jenis tumbuhan yang digunakan dalam upacara adat. Metode ini didukung dengan teknik pengumpulan data secara observasi partisipatif, dimana peneliti terlibat langsung dalam kegiatan upacara adat serta wawancara terhadap informan kunci dan responden menggunakan tipe wawancara semi terstruktur, wawancara bebas dan wawancara mendalam (Martin, 1995; Albuquerque $d k k ., 2014$ ).

Informan kunci ditentukan dengan menggunakan metode snowballing berdasarkan atas petunjuk dan rekomendasi dari kepala desa dan masyarakat terhadap seseorang yang dianggap mampu memberikan informasi sesuai kebutuhan penelitian. Informan kunci yang terpilih adalah tokoh-tokoh adat (mosalaki) yang terdiri dari mosa nua (pemimpin/kepala kampung), mosa woe (pemimpin/ketua suku) dan soma (kepala rumah adat) yang berjumlah 15 orang. Sedangkan responden ditentukan secara purposive sampling dengan batasan usia 17 tahun ke atas, merupakan penduduk asli etnis Ngadha, bertempat tinggal di lokasi penelitian, sehat jasmani dan rohani. Jumlah keseluruhan responden yaitu 93 orang.
Kegiatan identifikasi tumbuhan dilakukan langsung di lapangan dan apabila tidak diketahui datanya secara lengkap, maka dibuat herbarium guna dilanjutkan proses identifikasi di laboratorium Ekologi dan Biosistematika, Fakultas Sains dan Matematika, Universitas Diponegoro. Identifikasi tumbuhan mengacu pada sumber-sumber seperti Flora of Java (Backer and Brink), Flora untuk sekolah di Indonesia (Steenis, 2003) dan Tumbuhan berguna Indonesia Jilid I, III dan III (Heyne, 1987).

\section{Hasil dan Pembahasan}

Adat -istiadat di wilayah Jerebu'u masih sangat kental dengan berbagai aturan dan norma adat yang berlaku. Kehidupan sosial etnis Ngadha masih mengenal strata/tingkatan/rang yang dibagi dalam 3 strata yaitu ga'e meze (golongan bangsawan utama), ga'e kisa (golongan bangsawan tengah) dan ho'o (orang-orang kecil/budak). Masyarakat di wilayah ini pada umumnya sudah memeluk agama Katolik namun secara eksplisit masih ada kepercayaan asli yang didasarkan pemujaan kepada Tuhan dan leluhur yang tercampur dengan animisme dan dinamisme (Arndt, P., 2005; Jayanti, 2012).

Berbagai kegiatan upacara adat masih terus dijalankan oleh masyarakat ini seperti upacara yang berkaitan dengan siklus hidup, upacara Reba (tahun baru adat) biasa dilakukan sekali dalam setahun yang berlangsung dari bulan Desember sampai Februari, upacara pembuatan situs-situs penting seperti Ngadhu dan Bhagha, upacara pembuatan rumah adat ( $T a u$ Sa'o) dan upacara yang berkaitan dengan pertanian.

\subsection{Keanekaragaman Jenis Tumbuhan dalam Upacara Adat Etnis Ngadha}

Berdasarkan hasil penelitian diperoleh 60 jenis tumbuhan tergolong dalam 26 famili yang digunakan sebagai kelengkapan upacara adat etnis Ngadha Beragam jenis tumbuhan yang dimanfaatkan sebagai bahan pelengkap upacara adat etnis Ngadha didominasi oleh beberapa jenis tumbuhan dari famili yang berbeda. Famili yang paling banyak digunakan adalah Poaceae 15 jenis (25\%), Fabaceae 8 jenis (13\%), Arecaceae 6 jenis (10\%), Musaceae dan Solanaceae masing-masing 3 jenis (5\%), sedangkan famili lainnya 1 sampai 2 jenis $(<3 \%)$ Data di atas ditampilkan secara terperinci pada Gambar 1.

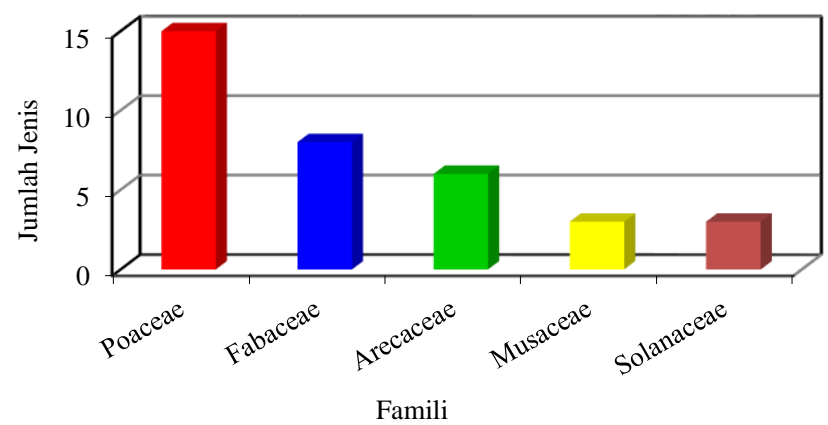

Gambar 1. Famili Tumbuhan yang Digunakan dalam Upacara Adat Etnis Ngadha

Bagi etnis Ngadha penggunaan tumbuhan dalam upacara adat masih sangat lekat dan dijaga keasliannya sesuai dengan warisan leluhur, dalam hal in hampir semua jenis tumbuhan yang digunakan dahulu dan sekarang tidak ada yang mengalami perubahan secara drastis. Hal ini terkait dengan kepercayaan masyarakat bahwa setiap jenis tumbuhan memiliki nilai-nilai spiritual dan makna tersendiri dalam adat yang didapatkan secara turun temurun. Sheil $d k k,(2004)$ mengemukakan bahwa biasanya masyarakat menggunakan berbagai jenis 
tumbuhan tertentu yang memiliki makna tersendiri bagi acara mereka dan merupakan aspek yang sangat penting di dalamnya.

Jenis tumbuhan terbanyak yang dimanfaatkan dari famili Poaceae diantaranya padi/pare (Oryza sativa $\mathrm{L}$ ), jagung/sae (Zea mays L), bambu aur/guru (Bambusa vulgaris var. vulgaris Schard.ex Wendl), bambu pri (Gigantochloa atter (Hassk) Kurz), bambu betung (Dendrocalamus asper (Schulth.F) Backer ex Heyne) dan bambu wuluh (Schizostachyum lima (Blanco) Merr) dan sereh (Cymbopogon citratus Stapf).

Penggunaan 'pare' (Oryza sativa) biasa dalam bentuk beras yang merupakan bahan baku utama sebagai nasi untuk sesajen dan makanan bagi peserta upacara adat. Masyarakat beranggapan bahwa sesajen yang dipersembahkan berupa nasi untuk leluhur (Ebu nusi) dan Tuhan (Dewa Zeta) sebagai simbol penghormatan karena padi atau nasi merupakan makanan yang hanya diperuntukkan bagi mereka yang mulia, besar dan berkuasa yang menurut Arndt (2005) disejajarkan dengan golongan bangsawan (ata ga'e). Beras dalam bentuk mentahan juga digunakan sebagai media berkat hewan kurban saat hendak dilakukan penyembelihan dan sebagai barang hantaran dari keluarga dan kenalan yang merupakan bagian dari bantuan bagi pihak keluarga lainnya yang mengadakan acara adat. Selain padi, jagung (Z. mays L) juga dimanfaatkan sebagai bahan makanan yang wajib disediakan dalam upacara tertentu seperti reba dan $t a{ }^{\prime} u a z i$ (kelahiran) yang disebut tabha. Jagung atau 'sae' dalam bentuk tepung dimanfaatkan sebagai bahan pengawet daging seperti daging babi, kerbau dan kuda yang disebut wu'u sui. Daging awetan ini disimpan dalam wadah yang terbuat dari bambu (tuku) dan daging yang akan digunakan biasanya telah disimpan sekitar 1 sampai 2 tahun.

Jenis bambu yang mempunyai makna penting dalam budaya orang Ngadha adalah bambu 'guru' (B. vulgaris var. vulgaris), pemanfaatannya sebagai su'a atau alat penggali yang menjadi suatu pengakuan hak milik tanah yang dibagikan atau diberikan leluhur kepada pribadi maupun kelompok suku (Dem, 1996). Su' menjadi salah satu barang pusaka yang dimiliki oleh setiap rumah adat dalam suatu woe /suku. Jenis bambu ini juga digunakan sebagai media peramalan yang dikenal dengan sebutan tibo. Watu (2016) menyatakan bahwa tibo digunakan sebagai media petunjuk atau 'guru' untuk mengetahui suatu keadaan di masa lalu atau masa depan, petunjuk keberadaan terhadap sesuatu atau tempat yang terkait dengan maksud dan tujuan pelaksanaan upacara adat.

Tumbuhan Cassia fistula Linn merupakan salah satu jenis tumbuhan dari famili Fabaceae yang penting dalam kebudayaan etnis Ngadha, dimana batang tumbuhan ini digunakan sebagai tiang utama ngadhu yang merupakan monumen pengganti leluhur laki-laki dari suatu woe/suku yang terdapat di tengah kampung. Selain $n g a d h u$, ada monumen pengganti leluhur wanita yang disebut bhaga. Bangunan bhagha menyerupai bangunan rumah adat etnis Ngadha dalam ukuran yang lebih kecil dengan bahan utamanya dari dua jenis kayu yaitu 'fai' (Albizia sp; Fabaceae) dan 'oja' (Toona sureni Merr; Meliaceae). Atap bangunan ini terbuat dari alang-alang dan kerangka atapnya menggunakan bambu 'bheto' (Dendrocalamus asper) dan bambu pri (Gigantochloa atter). Jenis kayu yang digunakan sebagai bahan bangunan baik ngadhu maupun bhagha tidak dapat digantikan oleh jenis tumbuhan lainnya. Jumlah ngadhu dan bhagha yang terdapat di sebuah kampung menunjukkan jumlah suku yang ada di dalamnya.

Terdapat tujuh jenis tumbuhan famili Arecaceae yang digunakan sebagai bahan pelengkap upacara adat diantaranya pinang atau 'seu' (Areca catechu L.) digunakan sebagai persembahan untuk leluhur yang biasa disajikan pula bersama dengan sirih atau 'nata' (Piper betle L; Piperaceae). Selain sebagai persembahan, sirih dan pinang menjadi bahan jamuan bagi peserta upacara dan yang biasa disajikan pada awal pelaksanaan upacara adat sebagai bentuk penghormatan untuk tamu, simbol kekerabatan dan persaudaraan. Perlengkapan menyirih (ngeu) seperti sirih, pinang (biji pinang muda dan biji pinang yang sudah dikeringkan) dan kapur biasanya selalu tersedia selama kegiatan adat berlangsung.

Air nira hasil sadapan dari pohon aren atau 'moke' (Arenga pinnata) digunakan sebagai minuman tradisional yang disebut moke atau tua bhara. Umumnya dalam kehidupan orang Ngadha nira aren yang digunakan dalam upacara adat adalah nira yang sudah mengalami fermentasi sehingga menghasilkan nira yang mengandung alkohol dengan kadar yang rendah. Moke merupakan sesajen utama untuk leluhur dan minuman peserta upacara adat yang diibaratkan sebagai air susu ibu (wae susu ine) pemberi kehidupan bagi manusia. Pisang (Musa spp) merupakan jenis tumbuhan dengan banyak kegunaan, dalam upacara adat etnis Ngadha pisang sebagai simbol kemakmuran dan kesuburan. Salah satu jenis tumbuhan dari famili Solanaceae yang digunakan dalam upacara adat yaitu terung kecil 'bara kedhi' (Solanum sp.) sebagai bahan makanan dan penolak bala.

Selain itu terdapat jenis tumbuhan lainnya yang seperti uwi (Dioscorea alata L.) yang memiliki peran penting di dalam budaya orang Ngadha. Nilai penting uwi terlihat dalam upacara adat Reba yang mana uwi menjadi ikon utama. Uwi sebagai Simbol kemakmuran dan kejayaan dalam hidup orang Ngadha karena menjadi sumber makanan yang tidak pernah habis disediakan oleh bumi, mulai dari kehidupan para leluhur yang menjadikan uwi sebagai sumber makanan utama selama pengembaraan dan akhirnya menemukan jenis makanan lainnya seperti padi dan jagung. Sehingga uwi tidak saja bernilai memenuhi kebutuhan pokok manusia tetapi bernilai sejarah (Dem, 1996). Uwi juga digunakan dalam beberapa upacara adat masyarakat lokal lainnya seperti masyarakat suku Kanum di Papua yang menggunakan dua jenis Dioscorea yaitu Dioscorea alata dan Dioscorea esculenta sebagai mas kawin serta pelengkap pada upacara adat (Rauf \& Lestari, 2009).

\subsection{Organ Tumbuhan yang Digunakan}

Organ tumbuhan yang digunakan bervariasi dalam setiap pelaksanaan upacara adat etnis Ngadha. Berdasarkan hasil penelitian diperoleh bahwa organ tumbuhan yang digunakan meliputi daun, buah, biji, batang, umbi, kulit batang, dan pelepah. Selain penggunaan bagian tumbuhan secara terpisah, ada beberapa alat upacara yang menggunakan tumbuhan secara utuh dari akar hingga daun. Penggunaan organ tumbuhan dalam upacara adat etnis Ngadha dapat dilihat pada Gambar 2.

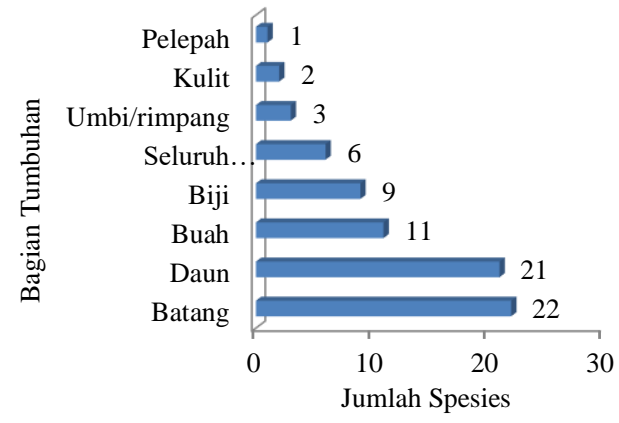

Gambar 2. Organ Tumbuhan yang Digunakan dalam Upacara Adat Etnis Ngadha

Bagian tumbuhan yang paling banyak digunakan adalah batang sebanyak 22 jenis (36\%) dan yang paling sedikit yaitu bagian pelepah sebanyak 1 jenis (2\%). Tingginya penggunaan organ batang tumbuhan dalam upacara adat etnis Ngadha karena sebagian besar sarana upacara menggunakan batang sebagai alat pikul, alat ukur, kayu bakar, bahan bangunan serta berbagai jenis peralatan lainnya. Pemanfaatan batang dipandang dari aspek kelestarian spesies tumbuhan yang bersangkutan dapat mengancam keberlangsungan hidupnya di alam sebab dapat membuat tumbuhan menjadi rusak bahkan mati. Hal ini dikaitkan dengan tempat serta kedudukan batang bagi tumbuhan yang merupakan sumbu tubuh tumbuhan. Hal positifnya bahwa organ batang yang digunakan dalam upacara adat sebagian besar berasal dari tumbuhan yang ketersediaannya cukup banyak di sekitar lingkungan, baik itu tanaman budidaya maupun liar. Selain itu, penggunaannya untuk jangka waktu yang lama seperti bahan bangunan dan aksesoris. Daun memiliki persentase penggunaan terbanyak setelah batang, daun digunakan sebagai bahan makanan, wadah sesaji yang terbuat dari anyaman daun lontar, pembungkus makanan, sebagai tanda atau petunjuk dan lain-lain. Organ daun banyak digunakan karena beberapa faktor diantaranya daun merupakan bagian tumbuhan yang mudah untuk diambil dan diolah, pada umumnya spesies tumbuhan memiliki daun yang tidak tergantung pada musim serta jumlah ketersediaan daun pada suatu spesies tumbuhan lebih besar dibandingkan bagian tumbuhan lainnya seperti akar, batang, bunga, kulit, buah, ataupun biji.

\subsection{Asal Tumbuhan yang Digunakan dalam Upacara Adat}

Berdasarkan asal tumbuhan dan hewan yang digunakan oleh masyarakat dikelompokkan menjadi dua yakni yang berasal dari hasil budidaya dan liar Berdasarkan persentase asal tumbuhan seperti pada Gambar 3. terlihat bahwa spesies tumbuhan dan yang paling banyak dimanfaatkan oleh masyarakat adalah hasil budidaya yang dilakukan di pekarangan rumah (kintal) dan kebun (uma).

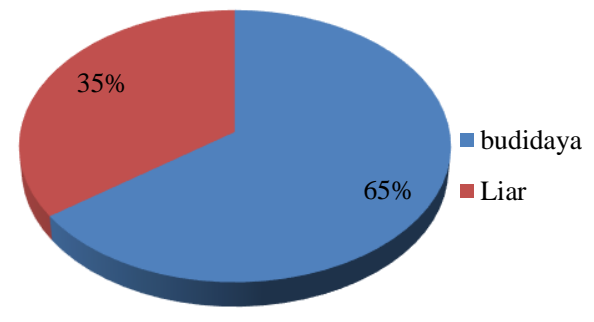

Gambar 3. Persentase Asal Tumbuhan dan Hewan yang Digunakan dalam Upacara Adat

Pada dasarnya budidaya yang dilakukan dengan alasan tumbuhantumbuhan tersebut merupakan tumbuhan yang mempunyai kegunaan ganda dalam kehidupan sehari-hari masyarakat misalnya bahan makanan, rempahrempah, obat-obatan, bahan bangunan dan komoditas perdagangan. Sedangkan spesies liar untuk tumbuhan biasanya diperoleh dari hutan dan tumbuhan yang meliar di sekitar pekarangan rumah atau pinggiran jalan desa. Tumbuhan liar ini juga mempunyai banyak kegunaan selain dalam pelaksanaan upacara adat sebagai kayu bakar, obat-obatan, pakan ternak dan kebutuhan lainnya. Namun jenis-jenis tumbuhan ini pada umumnya ketersediaannya yang melimpah di alam dan mudah ditemukan di semua habitat lingkungan.

\subsection{Upaya Konservasi}

Berdasarkan hasil penelitian masyarakat menuturkan bahwa peran dan makna penting setiap tumbuhan dalam upacara adat tidak dapat digantikan oleh 
jenis tumbuhan yang lainnya. Oleh karena itu, masyarakat melakukan kegiatan budidaya jenis-jenis tumbuhan di sekitar pekarangan rumah, kebun atau ladang milik mereka. Jenis-jenis tumbuhan yang digunakan dalam upacara adat diambil secukupnya sesuai dengan kebutuhan, pengambilan jenis tumbuhan tertentu membutuhkan tata cara adat yang sesuai agar makna nilai kesakralannya tidak hilang, hal ini dimaksudkan agar fungsi dari tumbuhan tersebut tercapai dalam penggunaannya.

Masyarakat Ngadha meyakini bahwa setiap tumbuhan memiliki jiwa namun tidak berbudi seperti manusia, jiwa mereka akan hilang ketika dirusakkan (Arndt, P., 2005). Lokasi pengambilannya juga ditentukan sesuai aturan dan tradisi masyarakat. Coto $d k k .$, (2004) menyatakan tanpa disadari pola-pola kehidupan masyarakat tradisional yang masih kuat dikuasai oleh nilai-nilai budaya dan norma sosial tradisional sangat membantu dalam upaya pelestarian sumberdaya hayati.

\section{Simpulan}

Tumbuhan yang digunakan dalam upacara adat berjumlah 60 jenis yang tergolong dalam 25 famili dan didominasi oleh famili Poaceae, Fabaceae, Arecaceae, Musaceae dan Solanaceae. Umumnya semua jenis tumbuhan yang digunakan mempunyai nilai dan makna yang penting sebagai bahan dan alat pelengkap dalam pelaksanaan upacara adat. Bentuk kegiatan pelestarian yang dilakukan masyarakat adalah budidaya di sekitar pekarangan rumah, kebun atau ladang serta pengambilan yang secukupnya sesuai dengan kebutuhannya.

\section{Pustaka}

Albuquerque, U., Cruz da Cunha, L.V.., Lucena, R.F.P. \& Alves, R.R.. 2014. Methods and Techniques Used to Collect Etnobiological Data. Methods and Techniques in Ethnobiology and Ethnoecology. Springer Protocols Handbooks, Humana Press. New York.

Arndt, P. 2005. Agama Orang Ngadha: Dewa, Roh-roh, Manusia dan Dunia (Vol.) diterjemahkan oleh Paulus Sabon. Maumere-Flores: Pusat Penelitian Agama dan Kebudayaan, Candraditya.

Arndt, P 2007. Agama Orang Ngadha: Kultus, Pesta dan Persembahan (Vol.II) diterjemahkan oleh Paulus Sabon. Maumere-Flores: Pusat Penelitian Agama dan Kebudayaan, Candraditya.

Coto, I.Z., Hardjanto, I. \& Rahayu, S. 2004. Pentingnya pengetahuan tradisional dalam konservasi keanekaragaman hayati.

Dem, Y. 1996. Budaya Ngadha dalam Proses Pembangunan Masyarakat dan Gereja. Surabaya: Agape 73 Printing.

Heyne, K. 1987. Tanaman Berguna Indonesia. Balai Penelitian dan Pengembangan Kehutanan. Departemen Kehutanan. Jakarta.

Jayanti, N. 2012. Sistem Religi dalam Komunitas Adat Kampung Bena. Widyariset 15 (1).

Martin, G.J. 1995. Ethnobotany: A method manual. Worldwide fund for Nature. chapman and hall, London.

Rauf, A.W. \& Lestari, M.S. 2009. Pemanfaatan komoditas pangan lokal sebagai sumber pangan alternatif di Papua. Jurnal Litbang Pertanian, 28(2): 5462.

Rohmah, S.A., Asyiah, I.N. \& Hariani, S.A. 2014. Etnobotani Bahan Upacara Adat Oleh Masyarakat Using di Kabupaten Banyuwangi.

Shell, D. 2004. Mengeksplorasi keaanekaragaman hayati, lingkungan dan pandangan masyarakat lokal mengenai berbagai lanskap hutan. Metodemetode penilaian lanskap secara multidisipliner. ISCRAF. Bogor.

Steenis 2003. Flora untuk Sekolah di Indonesia. Cetakan Kesembilan. Cetakan Kesembilan. Jakarta: PT. Pradnya Paramita.

Watu, Y. 2016. Tuhan, Manusia, dan Sa'o Ngaza: Kajian Filsafat Budaya Rumah Tradisional Orang Ngada-Flores. Yogyakarta: Penerbit PT Kanisius. 